\title{
Remote Psychosocial Rehabilitation (rPSR): A Broad View
}

\author{
Abraham Rudnick
}

Received: 15 June 2020/Accepted: 17 June 2020/Published online: 26 June 2020

(C) Springer Nature India Private Limited 2020

Psychosocial rehabilitation (PSR) facilitates recovery of people with mental health challenges by enhancing and maintaining their adaptive skills and supports (and preferably also the synergism of these skills and supports [1]). Traditionally, PSR has been conducted in-person (both individually and in groups), such as in supported education and employment [2]. Yet inperson PSR may not be feasible in extraordinary circumstances such as in the current (Coronavirus disease 2019; COVID-19) pandemic and in ordinary circumstances for individuals who live remotely; hence, providing PSR that is not in-person, i.e., remote PSR (rPSR), is needed in such circumstances. Although particular attention has been given recently to digital technology in order to address this need [3], a broader view is required to address it. This brief paper aims to innovate by providing such a broad view of rPSR, using a selective literature review to illustrate rPSR issues and related opportunities and challenges.

People with mental health challenges who live remotely, i.e., in places that are geographically distant from other communities and/or not easily accessible by ground, air and other transportation, cannot often

A. Rudnick $(\bowtie)$

Department of Psychiatry and School of Occupational Therapy, Dalhousie University, and Nova Scotia Operational Stress Injury Clinic, 210-100 Eileen Stubbs Avenue, Dartmouth, NS B3B1Y6, Canada

e-mail: harudnick@hotmail.com easily or at all access in-person PSR - and otherservices (an exception may be remote cities such as Perth in Australia where the critical mass of the large population supports comprehensive in-person services within the city's jurisdiction). Hence, rPSR is often needed in ordinary circumstances for individuals who live remotely [4]. In addition, in extraordinary circumstances such as the current (COVID-19) pandemic, in-person PSR is often not feasible due to public health restrictions related to social gathering and more. Hence, rPSR is often needed in extraordinary circumstances such as in the current (COVID-19) pandemic for many if not all PSR service users, in order to not neglect their needs as a socially disadvantaged population [5].

There are at least two distinct general approaches to the provision of rPSR. One approach is to train local people living in or near the service users' remote community/area (locals) - particularly training general practitioners and natural supports-to provide some PSR in their remote community. Another approach is to provide PSR from a distance, particularly by using synchronous and asynchronous digital services; note that voice only phone services are often feasible but are typically not sufficient for PSR. I address each of these approaches separately, recognizing that they can be combined, e.g., training locals may be done at a distance by using digital services.

Considerations related to training local general practitioners are considerably different from 
considerations related to training local natural supports. As for general practitioners (physicians, nurses, social workers and other human services providers), on the upside, they are experienced in providing some human (health and/or other) services, and PSR service users often have access to them. On the downside, general practitioners are busy with many other issues, and often require changing attitudes as well as enhancing knowledge and adding skills in relation to PSR [6, 7]. As for natural supports (family members, friends, peers and others), on the upside, they typically know the service user very well, and they are often committed to help the service user. On the downside, they may first require very basic training in human services, and they often lose hope-which is crucialfor the service user [8].

Considerations related to providing PSR at a distance by means of digital services (digital PSR; dPSR) can be separated into those addressing technology factors (hardware such as laptops or smart phones as well as software such as apps) and those addressing other factors. As for technology, on the upside, it is continuously improving, and it is expanding in reach. On the downside, it is still not easily accessible-financially or otherwise-to some people, particularly to people living remotely in poverty (who often have mental health challenges and are hence arguably especially in need of PSR), and it is often not evidence-based and hence requires particularly careful selection [9]. As for other factors, on the upside, there is growing private and public funding for digital services, and many people (including the general population in developed countries as well as many youth in developing countries) are versed in some digital technology. On the downside, many PSR practitioners may not be trained and/or comfortable yet with dPSR (although the current pandemic may be changing that considerably), and internet access is still not universally upheld as a human right [10].

In conclusion, there are various opportunities and challenges related to rPSR, viewed broadly. Arguably, dPSR (as both direct care to service users and indirect care via remote consultation and support to local providers) is not sufficient for rPSR; training locals such as general practitioners and natural supports in PSR is also an important part of rPSR. Overall, rPSR is promising and may be combined with in-person PSR, e.g., by combining dPSR with training locals in PSR. Further research and related policy development is needed to advance rPSR, e.g., in relation to studying the combination of dPSR with training locals in some PSR, as well as in relation to universally upholding internet access as a human right and consequently resourcing such access to all people across the world, including for people who live remotely in any country.

\section{References}

1. Rudnick A. Synergism of adaptive skills and supports in psychosocial rehabilitation: a theoretical inquiry. J Psychosoc Rehabil Ment Health. 2018;5(1):101-2.

2. Rudnick A, Mcewan R, Pallaveshi L, Wey L, Lau W, Alia L, Volkenberg L. Integrating supported education and supported employment for people with mental illness: a pilot study. Int J Psychosoc Rehabil. 2013;18(1):5-25.

3. Tal A, Torous J. The digital mental health revolution: opportunities and risks. Psychiatr Rehabil J. 2017;40(3):263-5.

4. Rudnick A, Copen J. Rural or remote psychiatric rehabilitation (rPSR). Psychiatr Serv. 2013;64(5):495.

5. Rudnick A. Social, psychological and philosophical reflections on pandemics and beyond. Societies. 2020;10(2):42.

6. Rudnick A, Eastwood D. Psychiatric rehabilitation education for physicians. Psychiatr Rehabil J. 2013;36(2):126-7.

7. Rudnick A. TEACH: a framework for recovery-oriented education and training. Int $J$ Psychosoc Rehabil. 2016;20(2):59-61.

8. Rudnick A. Burden of caregivers of mentally ill individuals in Israel: a family participatory study. Int $\mathrm{J}$ Psychosoc Rehabil. 2004;9(1):147-52.

9. Chahal A, Rudnick A. Selecting digital health technologies for validation and piloting by health care providers: a decision making perspective from Ontario. Int $\mathrm{J}$ Technol Assess Health Care. 2019;35(1):1-4.

10. Reglitz M, Rudnick A. Internet access as a right for realizing the human right to adequate mental (and other) health care. Int J Ment Health. 2020;49(1):97-103.

Publisher's Note Springer Nature remains neutral with regard to jurisdictional claims in published maps and institutional affiliations. 